\title{
Democracy in action: students as design partners
}

\section{Andrea Todd}

University of Chester, UK

Keywords: students as partners; student voice; curriculum design; feedback; democracy; Covid-19.

\section{The challenge}

As part of our institution's Covid-19 response, a decision was made to pre-record all lectures and to only deliver seminars live online. This posed a challenge for two third-year Law modules scheduled to be delivered as weekly, face-to-face, two-hour sessions integrating the traditional lecture and seminar.

The integrated model had been co-designed with students two years prior to the pivot online, and comprised a lecture followed immediately by an opportunity to 'learn by doing', applying new knowledge in a problem-based workshop. The model led to a significant increase in attendance and engagement for both modules and a commensurate increase in student achievement. As such, the advertised method of delivery had been central to some students' decision-making in registering for these optional modules.

The institutional requirement to split the lecture away from the workshop contradicted the integrated model co-designed with students. The challenge was thus to enable and empower current students to co-create design and delivery solutions that worked for them, whilst respecting the boundaries of these necessary institutional constraints.

\section{The response}

In the first live online session for both modules, a commitment was made to students: to respond in real time to their views on module structure and delivery. Students were viewed 
as collaborative partners (Cook-Sather, Bovill and Felton, 2017) entering genuine dialogue (Bovill, 2017) with the module leader.

For this to work, both students and module leader needed to agree to respect the democratic process: students would be given a vote on delivery design, but they (and the module leader) would have to agree to abide by the outcome of this vote.

I sought to encourage a participatory approach that would empower students to be 'authors of their own destiny' (Gravett, Kinchin and Winstone, 2020, p.2584). Whilst it was clear that students were best placed to shape module delivery, it was crucial to retain the vital elements of a successful problem-based workshop, including time spent working:

1. With the tutor setting up the problem and expectations of the response.

2. Alone to consider the response.

3. In a group learning from peers and producing an agreed answer.

4. In plenary, ensuring all students achieved the session's learning outcomes.

In week four of teaching, students were asked for input, in each module, as follows:

1. An in-session vote on whether to amend module delivery to allow for some workshop content to be recorded and accessed immediately after the relevant recorded lecture, rather than delivered live online (following more closely the intended classroom-based delivery pattern, and involving, in one sitting, watching the lecture, accessing a problem, spending time alone solving it, and immediately accessing a recording considering the issues raised).

2. An online survey asking for preferences (from a range of options informed by the parameters enabling a successful workshop) in relation to the following:

a. The proportion of time spent during online sessions in small groups (in Teams channels) versus 'thinking time' spent alone.

b. How to accommodate plenaries: in a large group (each module caters to 45 students) or in smaller sub-groups.

22 of 43 students from module one, and 20 of 44 students from module two, responded to the in-class poll, representing $100 \%$ of the students present during these sessions. 12 
students from module one, and 9 from module two, responded to the online survey. The generalisability of the online survey results should therefore be approached with caution.

In terms of time spent during sessions, the majority of online survey respondents across both modules ( $81 \%$ from module one; $85 \%$ from module two) voted to plenarise the workshops in smaller rather than larger groups. The majority of respondents in both modules (78\% in module one, $58 \%$ in module two) also voted to spend more time working in groups to solve the problems set, and less time considering the issues alone.

As for the delivery pattern, in module one's in-class vote, $76 \%$ voted to retain weekly live workshop sessions, thus rejecting the option of accessing recorded workshop content. However, for module two, $79 \%$ voted in favour of accessing recorded workshop content.

To take in these changes, it was necessary to redraft the module handbook for both modules and the timetable for module two. This was turned around within one week of the vote, and published to students by week five of teaching, demonstrating a commitment to responding to student voice in real time.

Once the new system was in place, student contributions during live online workshops increased notably, as did students' willingness to suggest enhancements anecdotally throughout the year, reflecting an increased confidence in the feedback process. At the end of the year, when surveyed on their views of the partnership approach utilised in both modules, students reported feeling 'appreciated', 'happy that our concerns and views [were] listened to', and mindful that the desire to include students had been 'motivated by getting the best out of us'. The benefit of having a vote was appreciated by students even when their selection did not take the majority vote: '[t]his worked out really well, I [...] voted against $[\ldots]$ initially but it was excellent.'

Both modules had promised students the same delivery pattern. However, in voting for how to proceed with recorded workshops, the majority in each module came to opposing conclusions. This outcome could not have been predicted; indeed, the profile of students who select these modules is similar (in many cases students take both modules concurrently). It is clear that what worked for a group of students in one module would not have worked for the same group in the other module. The importance of academics not making assumptions about 'what works' is therefore underlined. 


\section{Recommendations}

This 'democracy in action' approach was born from a crisis. However, the positive student response to this partnership experience indicates that it could, and should, be rolled out in a more considered and purposeful fashion in future years and across other modules.

The learning points to take from this experience are as follows:

1. It is important that students feel part of the process.

2. It is crucial for students (and academic staff) to respect the outcome of the democratic process.

3. Academics must not make assumptions about the potential results of the democratic process.

4. It is important to frame the choices available to students in a way that ensures that whatever the outcome, the learning outcomes of each session, and the module, can be achieved.

Treating students as design partners does not mean giving students a free choice, but it does (and should) mean giving them a choice and honouring it.

\section{References}

Bovill, C. (2017) 'Breaking down staff-student barriers: moving towards pedagogic flexibility', in Kinchin, I. M. and Winstone, N. (eds.) Pedagogic frailty and resilience in the university. Rotterdam: Brill Sense, pp.151-161.

Cook-Sather, A., Bovill, C. and Felten, P. (2014) Engaging students as partners in learning and teaching: a guide for faculty. San Francisco: Jossey-Bass.

Gravett, I., Kinchin, M. and Winstone, N. E. (2020) 'More than customers: conceptions of students as partners held by students, staff, and institutional leaders', Studies in 
Higher Education, 45(12), pp.2574-2587.

https://doi.org/10.1080/03075079.2019.1623769.

\section{Author details}

Andrea Todd is Senior Lecturer in Law, Undergraduate Programme Leader and Director of Pro Bono and Community Engagement at the University of Chester. 